\title{
Phosphorylation of eIF2 $\alpha$ suppresses cisplatin-induced p53 activation and apoptosis by attenuating oxidative stress via ATF4-mediated HO-1 expression in human renal proximal tubular cells
}

\author{
SUNG-MIN JU ${ }^{1}$, YONG-SEOK JO ${ }^{1}$, YOO-MIN JEON ${ }^{1}$, HYUN-OCK PAE ${ }^{2}$, \\ DAE-GILL KANG ${ }^{3}$, HO-SUB LEE ${ }^{3}$, JUN-SANG BAE ${ }^{4}$ and BYUNG-HUN JEON ${ }^{1,5}$
}

\author{
${ }^{1}$ Department of Pathology, College of Korean Medicine; ${ }^{2}$ Department of Microbiology and Immunology, \\ School of Medicine; ${ }^{3}$ Hanbang Cardio-Renal Syndrome Research Center, Wonkwang University, Iksan, Jeonbuk 54538; \\ ${ }^{4}$ Department of Pathology, Chonbuk National University Medical School, Research Institute of Clinical Medicine \\ and Institute for Medical Sciences, Jeonju, Jeonbuk 54907; ${ }^{5}$ Research Center of Traditional Korean Medicine, \\ Wonkwang University, Iksan, Jeonbuk 54538, Republic of Korea
}

Received November 4, 2016; Accepted September 7, 2017

DOI: 10.3892/ijmm.2017.3181

\begin{abstract}
Cisplatin is one of the most widely used chemotherapeutic agents for the treatment of human cancers. However, the nephrotoxicity of cisplatin limits its use as a therapeutic agent. It has been suggested that oxidative stress and p53 activation play important roles in cisplatin-induced nephrotoxicity. It has been demonstrated that the eukaryotic translation initiation factor $2 \alpha$ (eIF $2 \alpha$ ) may protect HK-2 human renal proximal tubular cells against cisplatin-induced apoptosis through inhibition of reactive oxygen species (ROS)-mediated p53 activation. The aim of the present study was to investigate the effects of siRNA-mediated knockdown of the PKR-like endoplasmic reticulum kinase (PERK) gene, which induces the phosphorylation of eIF2 $\alpha$, or Sal003, a selective inhibitor of eIF $2 \alpha$ dephosphorylation, on cisplatin-induced apoptosis in HK-2 cells. Cisplatin induced eIF2 $\alpha$ phosphorylation as well as p53 activation. In particular, inhibition of p53 by pifithrin- $\alpha$, and upregulation of eIF $2 \alpha$ phosphorylation by Sal003, reduced cisplatin-induced apoptosis. Of note, Sal003-mediated upregulation of eIF2 $\alpha$ phosphorylation suppressed cisplatin-induced
\end{abstract}

Correspondence to: Professor Byung-Hun Jeon, Department of Pathology, College of Korean Medicine, Wonkwang University, 460 Iksandae-ro, Iksan, Jeonbuk 54538, Republic of Korea

E-mail: omdjbh@wku.ac.kr

Dr Jun-Sang Bae, Department of Pathology, Chonbuk National University Medical School, Research Institute of Clinical Medicine and Institute for Medical Sciences, 20 Geonji-ro, Deokjin-gu, Jeonju, Jeonbuk 54907, Republic of Korea

Email: jsbae78@jbnu.ac.kr

Key words: activating transcription factor 4, eukaryotic translation initiation factor $2 \alpha$, cisplatin, HK-2 cells, heme oxygenase-1, nephrotoxicity, $\mathrm{p} 53$, reactive oxygen species p53 activation. Furthermore, reduction of eIF2 $\alpha$ phosphorylation by PERK knockdown enhanced cisplatin-induced p53 activation and apoptosis. In addition, the ROS scavenger $N$-acetyl-L-cysteine inhibited eIF $2 \alpha$ phosphorylation as well as p53 activation in HK-2 cells treated with cisplatin, suggesting that oxidative stress induced by cisplatin may lead to apoptosis through p53 activation; furthermore, this stress may confer resistance to apoptosis via eIF2 $\alpha$ phosphorylation, which was further supported by the finding that cisplatin-induced ROS generation was attenuated by Sal003, whereas it was enhanced by PERK knockdown. Furthermore, cisplatin induced the expression of activating transcription factor 4 (ATF4) and heme oxygenase-1 (HO-1) that were enhanced by Sal003 and reduced by PERK knockdown. Taken together, these results suggest that phosphorylation of eIF $2 \alpha$ suppresses cisplatin-induced p53 activation and apoptosis by attenuating oxidative stress via ATF4-mediated HO-1 expression in HK-2 cells, as ATF4 expression is usually dependent on the phosphorylation of eIF $2 \alpha$ and may also transcriptionally induce the expression of HO-1 in response to oxidative stress. Therefore, regulation of eIF $2 \alpha$ phosphorylation may play an important role in alleviating cisplatin-induced nephrotoxicity.

\section{Introduction}

Cisplatin [cis-diamminedichloroplatinum(II)] is a potent chemotherapeutic agent, which is widely used for the treatment of human cancers $(1,2)$. However, the clinical application of cisplatin is limited by nephrotoxicity, leading to acute renal failure (3-6). Cisplatin accumulates predominantly in the kidney, as this is the major route for its excretion (7). Therefore, cisplatin nephrotoxicity appears to be associated with its accumulation in the kidney.

Cisplatin nephrotoxicity is a complex multifactorial process, including oxidative stress, mitogen-activated protein kinases, p53 tumor suppressor and inflammation (8). In 
particular, reactive oxygen species (ROS) and p53 have been shown to be important factors contributing to cisplatin nephrotoxicity. Cisplatin induces oxidative stress by generating ROS in renal cells, which leads to the activation of apoptotic pathways (9-11). p53 is activated during cisplatin nephrotoxicity and contributes to renal cell injury and death (12). Of note, p53 may be activated by ROS during cisplatin treatment of renal cells $(13,14)$. Moreover, ROS scavengers and p53 inhibitors may prevent cisplatin-induced apoptosis by suppressing the activation of p53 in renal cells (13-15). This suggests that regulation of p53 activity may be an important target for alleviating cisplatin nephrotoxicity.

Cisplatin nephrotoxicity is also associated with endoplasmic reticulum (ER) stress (16). Pre-activation of ER stress alleviates cisplatin-induced nephrotoxicity in various renal cell lines (17). ER stress, which may be observed under physiological or pathological conditions (18), is caused by accumulation of unfolded proteins in the ER. This accumulation attenuates mRNA translation through activation of PKR-like ER kinase (PERK) and subsequent phosphorylation of eukaryotic translation initiation factor $2 \alpha$ (eIF2 $\alpha$ ) (19). ER stress is involved in the stabilization of p53 through inhibiting ubiquitin-mediated degradation of p53. Qu et al have reported that ER stress prevents p53 stabilization and p53-mediated apoptosis upon DNA damage (20). Lee and Kim have also reported that ER stress-mediated eIF $2 \alpha$ phosphorylation attenuates cell death by inhibiting p53 stabilization in statin-induced apoptosis (21). Thus, it is most likely that eIF2 $\alpha$ phosphorylation plays an important role in the regulation of p53 expression or stability.

The aim of the present study was to investigate whether cisplatin induces p53-mediated apoptosis and ER stress-mediated eIF $2 \alpha$ phosphorylation in human renal proximal tubular HK-2 cells. In addition, since eIF $2 \alpha$ phosphorylation has been implicated in the stabilization of p53, which is due to p53 phosphorylation, the effect of ER stress-mediated eIF $2 \alpha$ phosphorylation on $\mathrm{p} 53$-mediated apoptosis induced by cisplatin was investigated in HK-2 cells.

\section{Materials and methods}

Reagents and antibodies. Cisplatin, dimethyl sulfoxide (DMSO), 2',7'-dichlorofluorescein diacetate (DCFH-DA), 3-(4,5-dimethylthiazol-2-yl)-2,5-diphenyltetrazolium bromide (MTT), $N$-acetyl-L-cysteine (NAC), propidium iodide (PI), protease inhibitor cocktail, ribonuclease A (RNase A) and anti- $\beta$-actin (sc-69879) antibody were all purchased from Sigma-Aldrich (St. Louis, MO, USA). Pifithrin- $\alpha$ and Sal003 were purchased from Calbiochem (La Jolla, CA, USA). Dulbecco's modified Eagle's medium (DMEM/F12) $(1: 1)$, fetal bovine serum (FBS) and antibiotic-antimycotic solution were all purchased from Gibco/Thermo Fisher Scientific, Inc. (Grand Island, NY, USA). Anti-rabbit cleaved-caspase-3 (Asp175) (no. 9661), anti-rabbit PARP (no. 9542), anti-rabbit phospho-p53 (Ser15) (no. 9284), anti-rabbit p53 (no. 9282), anti-rabbit phospho-eIF2 $\alpha$ (Ser51) (no. 9721), anti-rabbit eIF2 $\alpha$ and anti-rabbit activating transcription factor 4 (ATF4) (no. 11815) antibodies were all purchased from Cell Signaling Technology Inc. (Beverly, MA, USA). Anti-mouse heme oxygenase-1 (HO-1) (ADI-OSA-110) antibody was purchased from Enzo Life Sciences, Inc. (Farmingdale, NY, USA). Control siRNA and PERK siRNA (h) were both purchased from Santa Cruz Biotechnology, Inc. (Santa Cruz, CA, USA).

Cell culture. Immortalized human renal proximal tubular epithelial (HK-2) cells were obtained from the American Type Culture Collection (Manassas, VA, USA). The cells were maintained in DMEM/F12 (1:1) supplemented with 10\% FBS in 1:100 dilution of an antibiotic-antimycotic solution at $37^{\circ} \mathrm{C}$ in a $5 \% \mathrm{CO}_{2}$ incubator. Exponentially growing cells were seeded into a culture dish at $1 \times 10^{5}$ cells $/ \mathrm{ml}$ in complete medium for $24 \mathrm{~h}$ prior to treatment with chemicals.

Cell viability assay. Cell viability was determined by the colorimetric MTT metabolic activity assay. HK-2 cells were seeded at a density of $5 \times 10^{4}$ cells/well in a 24 -well plate. The cells were treated with different concentrations of cisplatin for $24 \mathrm{~h}$. After treatment, $500 \mu \mathrm{l}$ of MTT solution $(0.5 \mathrm{mg} / \mathrm{ml}$ in serum-free medium) was added to each well. After incubation for $4 \mathrm{~h}$ at $37^{\circ} \mathrm{C}$ in the dark, the MTT-containing medium was removed by aspiration. The generated blue formazan product was dissolved by the addition of $200 \mu 1100 \%$ DMSO per well. The amount of formazan was determined at $570 \mathrm{~nm}$ using the SpectraMax 250 microplate reader (Molecular Devices, Sunnyvale, CA, USA). The percentage of viable cells was calculated as follows: Mean optical density (OD) of treated cells/mean OD of control cells x100.

Flow cytometric analysis. The percentage of apoptotic cells was quantitated by PI staining and flow cytometric analysis, where the sub-G1 peak represented apoptotic cells. The HK-2 cells exposed to cisplatin were harvested, washed with ice-cold phosphate-buffered saline (PBS; pH 7.4), and fixed in $1 \mathrm{ml}$ of $70 \%$ ice-cold ethanol in PBS at $4^{\circ} \mathrm{C}$ for $1 \mathrm{~h}$. After removing the ethanol by repeated washing in PBS, cells were resuspended in $1 \mathrm{ml}$ of PI/RNase A solution (PBS with $10 \mu \mathrm{g} / \mathrm{ml} \mathrm{PI}$ and $100 \mu \mathrm{g} /$ $\mathrm{ml}$ RNase A) and incubated in the dark at $37^{\circ} \mathrm{C}$ for $1 \mathrm{~h}$. The sub-G1 DNA contents were quantified using Fluorescence-Activated Cell Sorting Calibur and CellQuest Pro software (both from BD Biosciences, San Jose, CA, USA).

Caspase-3 activity assay. The activity of caspase-3 was determined by the caspase-3 colorimetric assay kit (Abcam, Cambridge, MA, USA) according to the manufacturer's instructions. Briefly, cells were harvested after treatment, washed with PBS, and then lysed in lysis buffer. The cell lysates were centrifuged at $10,000 \mathrm{x}$ g for $1 \mathrm{~min}$, and $50 \mu \mathrm{l}$ of extracts containing $50 \mu \mathrm{g}$ protein were incubated with $50 \mu \mathrm{l}$ of $2 \mathrm{X}$ reaction buffer and $5 \mu \mathrm{l}$ of $4 \mathrm{mM}$ DEVD-pNA substrate at $37^{\circ} \mathrm{C}$ for $2 \mathrm{~h}$ in the dark. The colorimetric release of p-nitroaniline from DEVD-pNA substrate was measured at $405 \mathrm{~nm}$ using the SpectraMax 250 microplate reader. The percentage of caspase-3 activity was calculated as follows: Mean OD of treated cells/mean OD of control cells x 100 .

siRNA transfection. Transfection of siRNAs was performed using Lipofectamine 3000 reagent (Invitrogen/Thermo Fisher Scientific, Carlsbad, CA, USA) according to the manufacturer's instructions. HK-2 cells were seeded at a density of $2 \times 10^{5}$ cells in $60-\mathrm{mm}$ dishes, cultured in complete 

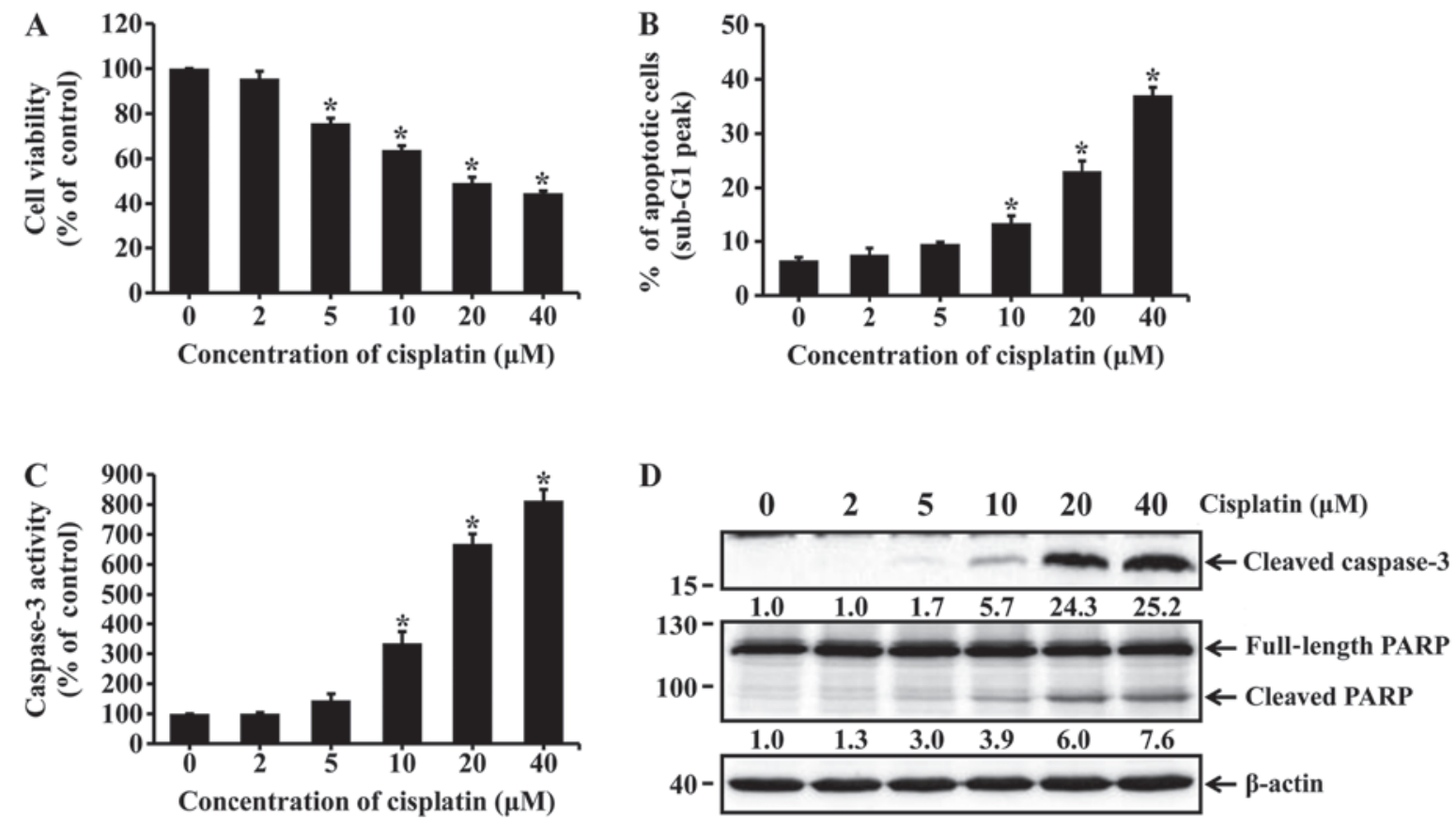

Figure 1. Effects of cisplatin on cytotoxicity, caspase-3 activation and poly(ADP-ribose) polymerase (PARP) cleavage in HK-2 cells. The cells were treated with various concentrations of cisplatin for $24 \mathrm{~h}$. (A) Cell viability was determined with the MTT assay. (B) Apoptotic cells were quantified by flow cytometry following staining with propidium iodide. (C) Caspase- 3 activity was measured using a caspase- 3 colorimetric assay kit. Values are presented as means \pm SD, $\mathrm{n}=3$. ${ }^{*} \mathrm{P}<0.05$ vs. untreated cells. (D) The expression levels of cleaved caspase-3 and PARP were examined by western blot analysis using anti-cleaved caspase-3 (p20) and anti-PARP antibodies. The numbers below the bands indicate the relative density ratio of the respective protein normalized to the internal control ( $\beta$-actin).

medium for $24 \mathrm{~h}$, and transfected with control or PERK siRNAs. The siRNAs were diluted to $200 \mathrm{nM}$ with $250 \mu \mathrm{l}$ of Opti-MEM. Lipofectamine 3000 reagent was also diluted 1:50 in Opti-MEM. Diluted siRNAs and Lipofectamine 3000 reagent were mixed in equal volumes and incubated for $15 \mathrm{~min}$ at room temperature. The mixtures were added to culture dishes containing $2 \mathrm{ml}$ fresh serum-free medium, and incubated at $37^{\circ} \mathrm{C}$ in a $5 \% \mathrm{CO}_{2}$ incubator for $24 \mathrm{~h}$. Thereafter, complete medium was added, the cells were further incubated for $24 \mathrm{~h}$ and subjected to the experiments.

ROS production assay. The relative levels of ROS were determined by the DCFH-DA fluorescence assay. HK-2 cells were seeded into 96 -well microplates $\left(1 \times 10^{4}\right.$ cells/well) for $24 \mathrm{~h}$ and incubated in Hank's Balanced Salt Solution (HBSS; pH 7.4) containing $20 \mu \mathrm{M}$ DCFH-DA at $37^{\circ} \mathrm{C}$ for $1 \mathrm{~h}$. Following incubation, the cells were washed with HBSS and treated with $40 \mu \mathrm{M}$ cisplatin under HBSS for the indicated time periods. The relative DCF fluorescence intensity was determined with an excitation wavelength of $485 \mathrm{~nm}$ and an emission wavelength of $538 \mathrm{~nm}$ using the SpectraMax M2 multi-mode microplate reader (Molecular Devices).

Western blot analysis. The cells were lysed in RIPA lysis buffer containing $1 \%$ halt protease and phosphatase inhibitor cocktails. Cell lysates were centrifuged at 20,000 x g for $15 \mathrm{~min}$ at $4^{\circ} \mathrm{C}$, and the protein concentration was determined using a Bradford assay. Samples containing $50 \mu \mathrm{g}$ of total protein were resolved by SDS-PAGE gel and transferred onto a nitrocellulose membrane for $3 \mathrm{~h}$ at $40 \mathrm{~V}$. The membranes were blocked with Tris-buffered saline with Tween-20 (20 mM Tris- $\mathrm{HCl}$,
$\mathrm{pH} 7.6 ; 150 \mathrm{mM} \mathrm{NaCl}$; and $0.05 \%$ Tween-20) containing $5 \%$ non-fat dry milk and probed with primary antibodies (all $1: 1,000$ in $3 \%$ BSA in Tris-buffered saline with $0.05 \%$ Tween20) overnight at $4^{\circ} \mathrm{C}$ with gentle shaking. Protein spots were detected using horseradish peroxidase-conjugated secondary antibodies (all 1:2,000 in 3\% BSA in Tris-buffered saline with $0.05 \%$ Tween-20). Immunoreactive bands were visualized using the SuperSignal West Pico Chemiluminescent Substrate kit (Thermo Fisher Scientific, Inc., Waltham, MA, USA) and then developed using the FluorChem E system (ProteinSimple, San Jose, CA, USA). The density of the bands was quantitated using Quantity One software, version 4.6.6 (Bio-Rad Laboratories, Inc., Hercules, CA, USA).

Statistical analysis. Statistical analysis was performed using Microsoft Office Excel 2013 (Microsoft, Redmond, WA, USA) and data are expressed as means \pm standard deviation. The statistically significant differences between two groups were calculated using the Student's t-test. P-values $<0.05$ were considered to indicate statistically significant differences.

\section{Results}

Cisplatin induces apoptotic cell death in HK-2 cells. HK-2 cells were incubated with different concentrations of cisplatin for $24 \mathrm{~h}$. Cell viability was assessed by the MTT assay. Apoptotic cells were determined using flow cytometry with PI staining. The viability of HK-2 cells markedly decreased with increasing concentrations of cisplatin (Fig. 1A). The percentage of apoptotic cells was significantly increased among cisplatin-treated cells (10, 20 and $40 \mu \mathrm{M}$ cisplatin) 
A $40 \mu \mathrm{M}$ Cisplatin
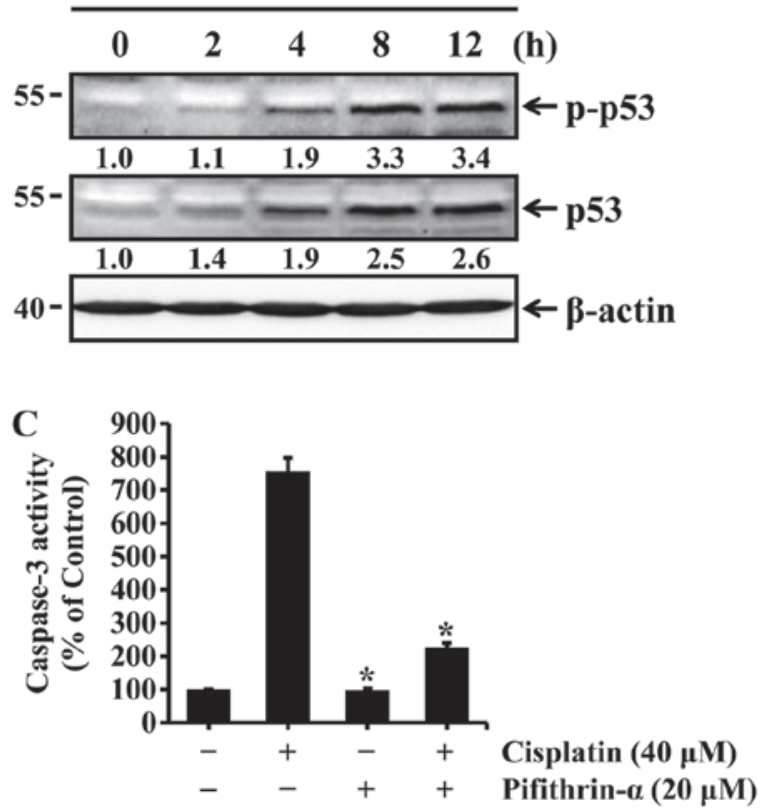

B

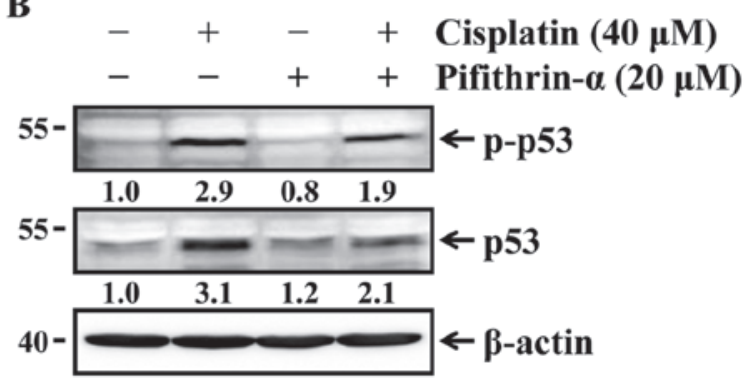

D

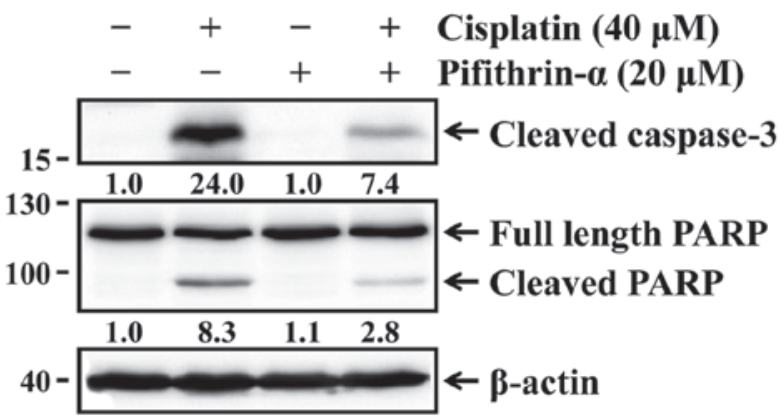

Figure 2. Effects of p53 activation on cisplatin-induced apoptosis in HK-2 cells. (A) The cells were incubated with $40 \mu \mathrm{M}$ cisplatin for the indicated times. (B-D) The cells were pretreated with or without $20 \mu \mathrm{M}$ pifithrin- $\alpha$ for $1 \mathrm{~h}$ and then exposed to $40 \mu \mathrm{M}$ cisplatin for 8 or $24 \mathrm{~h}$. Phosphorylation and expression of p53, cleaved caspase-3 and poly(ADP-ribose) polymerase (PARP) levels were examined by western blot analysis using anti-phospho-p53 (Ser15), anti-p53, anti-cleaved caspase-3 (p20) and anti-PARP antibodies. The numbers below the bands indicate the relative density ratio of the respective protein normalized to the internal control ( $\beta$-actin). Caspase-3 activity was measured using a caspase- 3 colorimetric assay kit. Values are presented as means \pm standard deviation, $\mathrm{n}=3$. ${ }^{*} \mathrm{P}<0.05$ vs. cells treated with cisplatin alone.

compared with the untreated cells (Fig. 1B). Caspase-3 activation and poly(ADP-ribose) polymerase (PARP) cleavage were determined by using caspase- 3 colorimetric assay kit and western blot analysis. As shown in Fig. 1C and D, treatment of HK-2 cells with cisplatin significantly increased the activity of caspase-3 and the levels of cleaved active caspase-3. Similarly, cisplatin treatment increased proteolytic cleavage of PARP to form an $89-\mathrm{kDa}$ fragment (Fig. 1D). These results indicate that cisplatin induced apoptotic cell death in HK-2 cells.

Cisplatin induces p53-mediated apoptosis in HK-2 cells. The tumor suppressor p53 plays an important role in regulating cisplatin-induced apoptosis of renal cells (13-15). Thus, we examined whether cisplatin could induce the activation of p53 via phosphorylation at serine 15 in HK-2 cells. HK-2 cells were treated with $40 \mu \mathrm{M}$ cisplatin for different times, and the expression and phosphorylation status of p53 were then determined by western blot analysis. The levels of total and phosphorylated p53, which is directly associated with p53 activation, were increased in a time-dependent manner (Fig. 2A), whereas pifithrin- $\alpha$, a specific p53 inhibitor, reduced p53 expression and phosphorylation in cells exposed to cisplatin (Fig. 2B). We next examined whether p53 activation was associated with cisplatin-induced apoptosis. HK-2 cells were treated with cisplatin in the absence or presence of pifithrin- $\alpha$, and caspase- 3 activation and PARP cleavage were then determined with the caspase- 3 colorimetric assay kit and western blot analysis. As shown in Fig. 2C and D, cisplatin-induced activation of caspase-3 and cleavage of PARP were markedly inhibited by pifithrin- $\alpha$. These results indicate that $\mathrm{p} 53$ activation is required for cisplatin-induced apoptosis in HK-2 cells.

Phosphorylation of eIF $2 \alpha$ suppresses cisplatin-induced p53 activation and apoptosis in HK-2 cells. Lee and Kim reported that the stabilization of p53 is affected by ER stress-mediated eIF2 $\alpha$ phosphorylation (21). p53 stability is associated with the phosphorylation of p53, which leads to stabilization of p53 by reducing its interaction with murine double minute 2 , a negative regulator of p53 (22). It was first examined whether cisplatin was able to induce phosphorylation of eIF2 $\alpha$ in HK-2 cells. The cells were treated with $40 \mu \mathrm{M}$ cisplatin for the indicated times, and the phosphorylation status of eIF $2 \alpha$ was then determined by western blot analysis. The levels of eIF $2 \alpha$ phosphorylation were increased time-dependently (Fig. 3A). Changes in the expression and phosphorylation status of p53 according to phosphorylation or dephosphorylation of eIF2 $\alpha$ were next examined in HK-2 cells exposed to cisplatin. The cells were pretreated with Sal003 to inhibit dephosphorylation of eIF $2 \alpha$, or transfected with siRNA against PERK to block PERK-eIF $2 \alpha$ phosphorylation prior to cisplatin treatment. As shown in Fig. 3B, Sal003 enhanced cisplatin-induced phosphorylation of eIF $2 \alpha$, and reduced expression and phosphorylation of p53 in cisplatin-treated cells. Furthermore, the siRNA-mediated knockdown of PERK completely blocked cisplatin-induced phosphorylation of eIF $2 \alpha$, and promoted expression of p53 and its phosphorylation in cisplatin-treated cells. Finally, it was investigated whether eIF $2 \alpha$-regulated p53 activation could be associated with cisplatin-induced apoptosis in HK-2 cells. As shown in Fig. 4, cisplatin-induced activation 
A
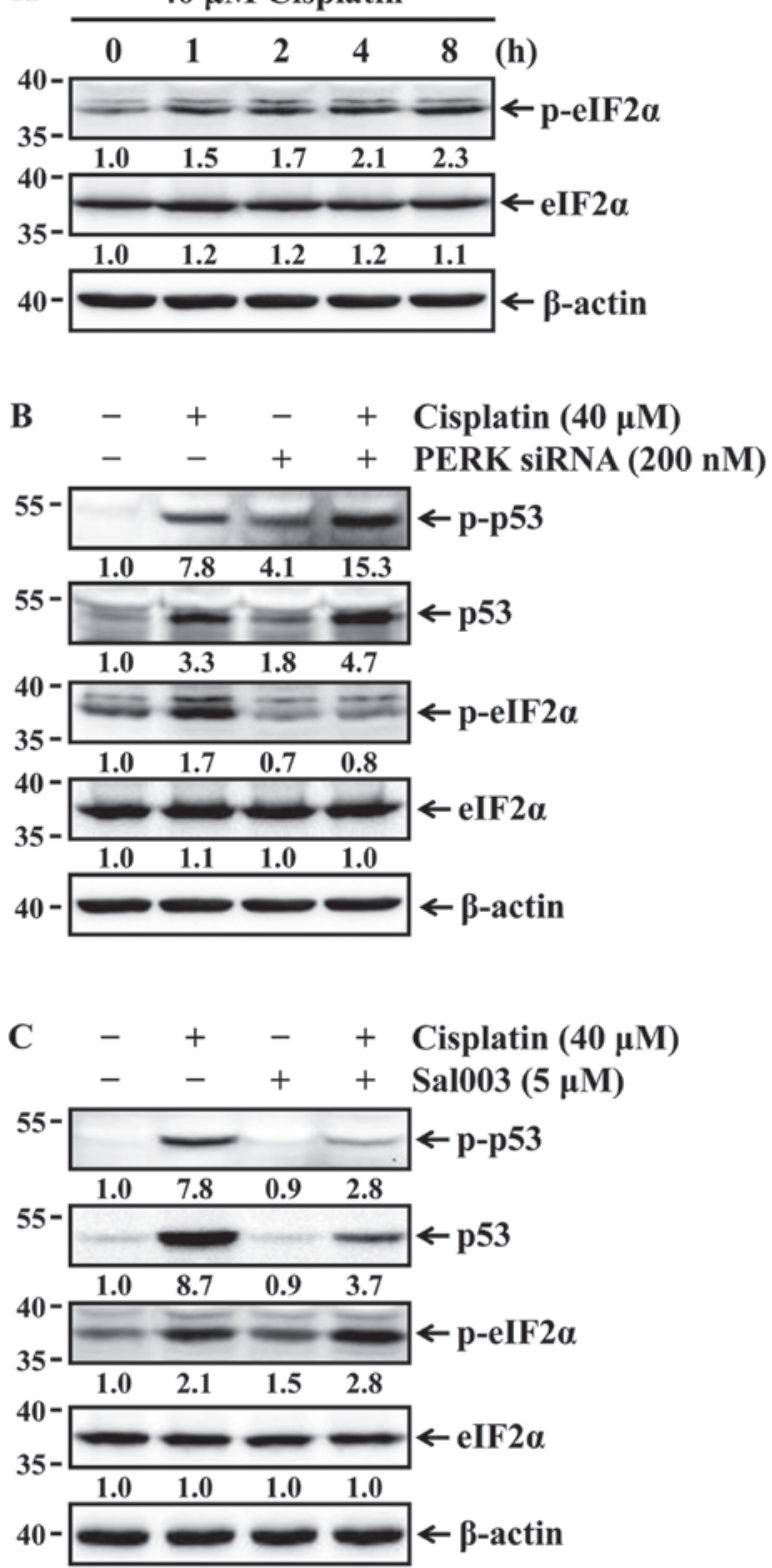

Figure 3. Effects of eukaryotic translation initiation factor $2 \alpha$ (eIF $2 \alpha$ ) phosphorylation on cisplatin-induced p53 activation in HK-2 cells. (A) The cells were incubated with $40 \mu \mathrm{M}$ cisplatin for the indicated times. (B) The cells were pretreated with or without $5 \mu \mathrm{M}$ Sal003 for $1 \mathrm{~h}$ and then exposed to $40 \mu \mathrm{M}$ cisplatin for $8 \mathrm{~h}$. (C) Cells transfected with $200 \mathrm{nM}$ control-siRNA or PKR-like endoplasmic reticulum kinase (PERK)-siRNA were incubated with or without $40 \mu \mathrm{M}$ cisplatin for $8 \mathrm{~h}$. The phosphorylation and expression levels of eIF $2 \alpha$ and p53 were examined by western blot analysis using anti-phospho-eIF2 $\alpha$ (Ser51), anti-eIF2 $\alpha$, anti-phospho-p53 (Ser15) and anti-p53 antibodies. The numbers below the bands indicate the relative density ratio of the respective protein normalized to the internal control ( $\beta$-actin).

of caspase-3 and cleavage of PARP were inhibited by Sal003, whereas they were promoted by PERK knockdown. These results indicate that phosphorylation of eIF $2 \alpha$ may confer resistance to cisplatin-induced apoptosis, at least in part, via p53 activation in HK-2 cells.

Oxidative stress is involved in cisplatin-induced eIF $2 \alpha$ phosphorylation and p53 activation in HK-2 cells. Similar to 553 , ROS is also known to play an important role in cisplatin-induced nephrotoxicity (13-15). Oxidative stress induced by ROS production is involved in p53 activation in cisplatin-induced renal cell injury. Therefore, it was examined whether cisplatin induced the production of ROS in HK-2 cells and, if so, whether it contributed to p53 activation. First, HK-2 cells were treated with $40 \mu \mathrm{M}$ cisplatin for the indicated times, and intercellular ROS production was then determined by measuring the fluorescence intensity of DCF. As shown in Fig. 5A, the levels of ROS production were significantly increased after $1 \mathrm{~h}$ of cisplatin treatment, and were maintained during prolonged cisplatin treatment. Previous studies have reported that $N$-acetylcysteine (NAC), a ROS scavenger, suppresses cisplatin-induced p53 activation in renal cells $(13,15)$. Therefore, the effect of ROS scavenging on cisplatin-induced p53 activation was examined in HK-2 cells. The cells were treated with cisplatin in the absence or presence of NAC, a general antioxidant, and the levels of total and phosphorylated p53 were then determined by western blot analysis. The levels of p53 expression and phosphorylation were almost completely blocked by NAC in cisplatin-treated cells (Fig. 5B). Since eIF $2 \alpha$ is phosphorylated mainly by PERK in response to oxidative stress, it was examined whether cisplatin-induced oxidative stress affects the phosphorylation of eIF $2 \alpha$ in HK-2 cells. As shown in Fig. 5B, the blockade of ROS production by NAC completely abolished the phosphorylation of eIF2 $\alpha$ in cells treated with cisplatin. Finally, changes in intracellular levels of ROS according to phosphorylation or dephosphorylation of eIF $2 \alpha$ were examined in HK-2 cells exposed to cisplatin. As shown in Fig. 5C, cisplatin-induced ROS production was suppressed by Sal003, whereas it was promoted by PERK knockdown. These results indicate that oxidative stress may mediate eIF $2 \alpha$ phosphorylation as well as p53 activation induced by cisplatin in HK-2 cells. In particular, phosphorylation of eIF $2 \alpha$ has been shown to exert a scavenging effect on cisplatin-induced ROS production in HK-2 cells.

Phosphorylation of eIF $2 \alpha$ induces ATF4 and HO-1 expression in cisplatin-treated HK-2 cells. Phosphorylation of eIF2 $\alpha$ by PERK selectively enhances the translation of ATF4 that induces the expression of genes involved in antioxidant response and apoptosis regulation (23). HO-1, which is a redoxsensitive microsomal enzyme, is known to be cytoprotective through its potent antioxidant effect in cisplatin-induced acute renal injury (8). Of note, ATF4 is able to transcriptionally induce the expression of the antioxidant gene HO-1 in response to oxidative stress $(24,25)$. Accordingly, it was investigated whether cisplatin was able to induce the expression of ATF4 and HO-1 in HK-2 cells. The cells were treated with $40 \mu \mathrm{M}$ cisplatin for the indicated times, and the expression of ATF4 and HO-1 was then determined by western blot analysis. Cisplatin time-dependently induced the expression of both ATF4 and HO-1 (Fig. 6A). It was next examined whether differences in the phosphorylation status of eIF $2 \alpha$ affected the expression levels of ATF4 and HO-1 in HK-2 cells exposed to cisplatin. As shown in Fig. 6B and C, cisplatin-induced ATF4 and HO-1 expression were elevated by Sal003 (Fig. 6B), while their expression was inhibited by PERK knockdown (Fig. 6C). These results indicate that phosphorylation of eIF2 $\alpha$ attenuates cisplatin-induced oxidative stress through ATF4-mediated HO-1 expression in HK-2 cells. 

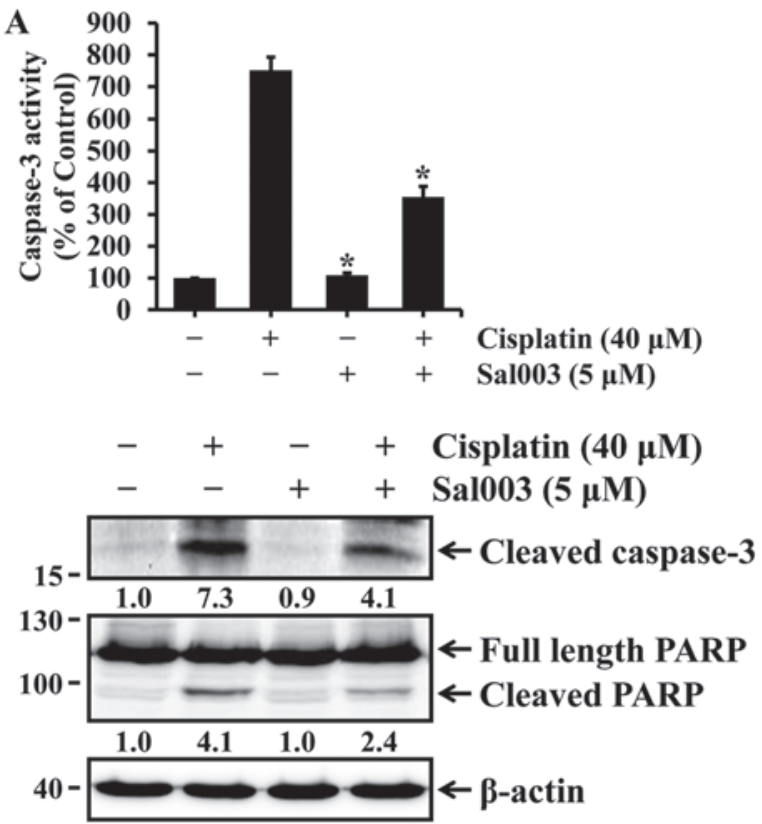
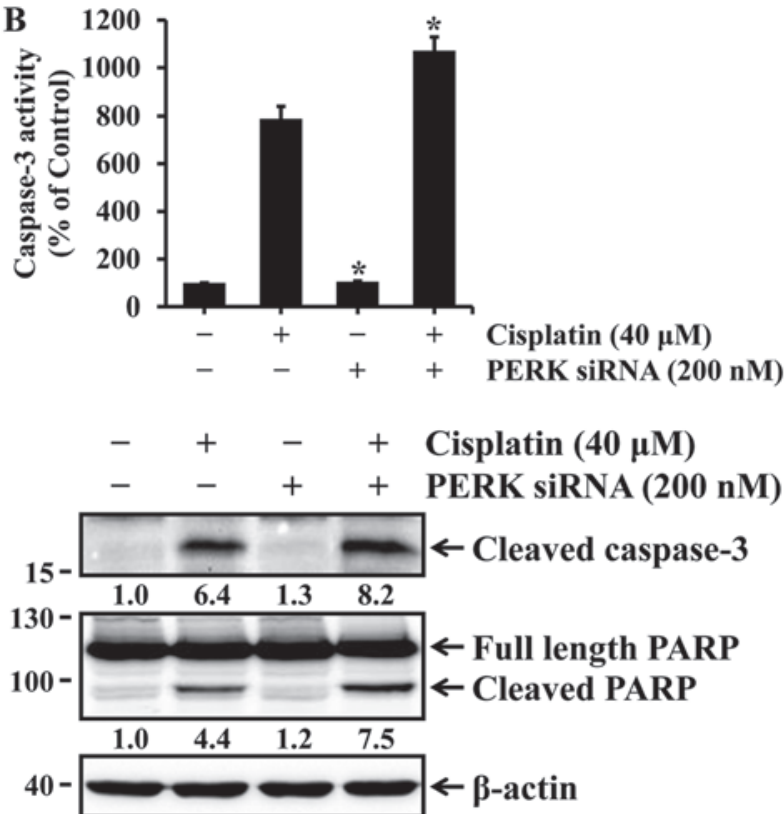

Figure 4. Effects of eukaryotic translation initiation factor $2 \alpha$ (eIF2 $\alpha$ ) phosphorylation on cisplatin-induced apoptosis in HK-2 cells. (A) The cells were pretreated with or without $5 \mu \mathrm{M}$ Sal003 for $1 \mathrm{~h}$ and then exposed to $40 \mu \mathrm{M}$ cisplatin for $24 \mathrm{~h}$. (B) Cells transfected with $200 \mathrm{nM}$ control-siRNA or PKR-like endoplasmic reticulum kinase (PERK)-siRNA were incubated with or without $40 \mu \mathrm{M}$ cisplatin for $24 \mathrm{~h}$. Caspase-3 activity was measured using a caspase-3 colorimetric assay kit. Values are presented as means \pm standard deviation, $n=3$. ${ }^{*} \mathrm{P}<0.05$ vs. cells treated with cisplatin alone. The expression levels of cleaved caspase-3 and poly(ADP-ribose) polymerase (PARP) were examined by western blot analysis using anti-cleaved caspase-3 (p20) and anti-PARP antibodies . The numbers below the bands indicate the relative density ratio of the respective protein normalized to the internal control ( $\beta$-actin).
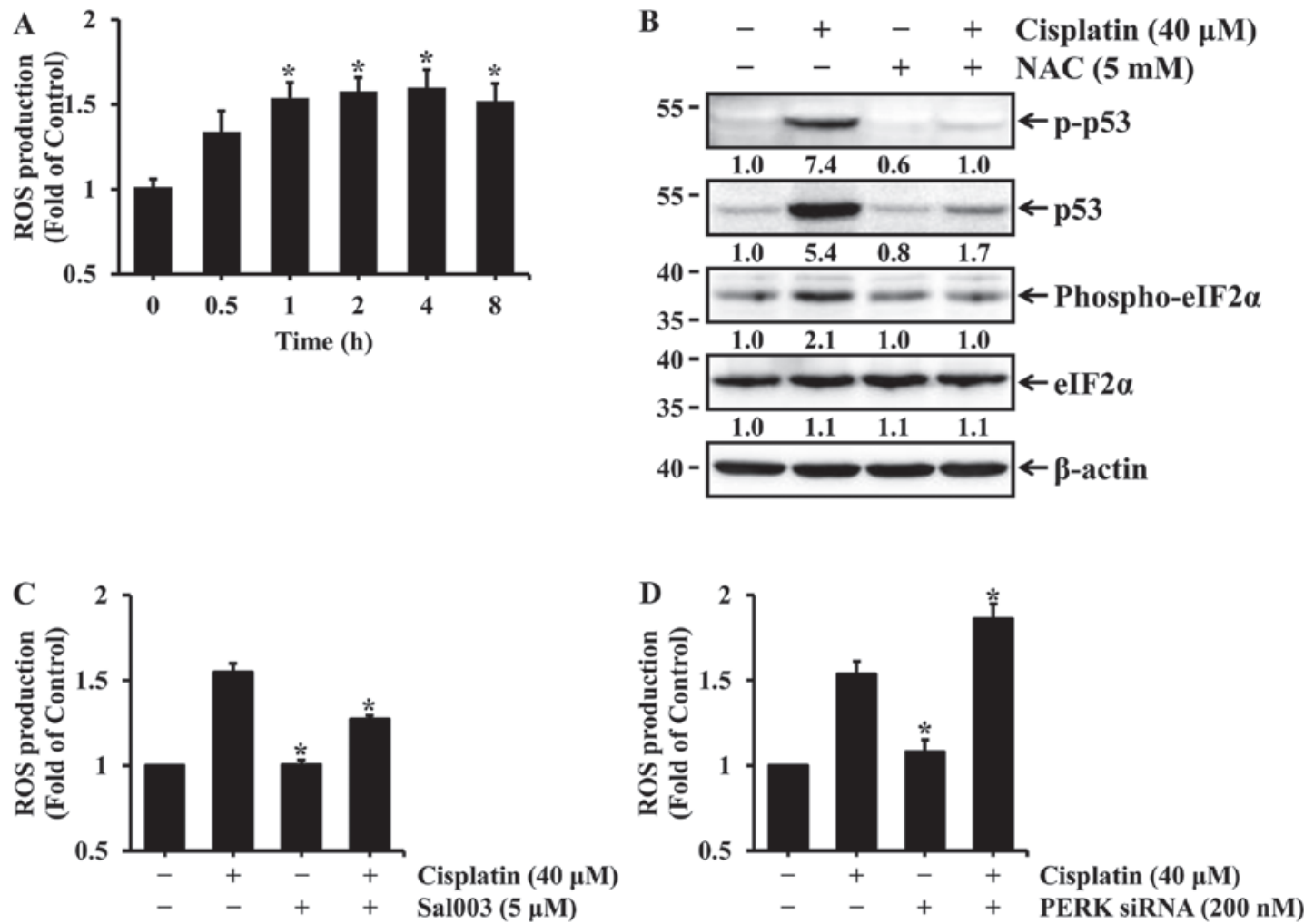

Figure 5. Effects of oxidative stress on cisplatin-induced eukaryotic translation initiation factor $2 \alpha$ (eIF2 $\alpha$ ) phosphorylation and p53 activation in HK-2 cells. (A) The cells were incubated with $40 \mu \mathrm{M}$ cisplatin for the indicated times. Reactive oxygen species (ROS) production was measured with the DCFH-DA fluorescence assay. Values are presented as means \pm standard deviation $(\mathrm{SD}), \mathrm{n}=3$. ${ }^{*} \mathrm{P}<0.05 \mathrm{vs}$. the $0 \mathrm{~h}$ timepoint. (B) The cells were pretreated with or without $5 \mathrm{mM}$ $N$-acetyl-L-cysteine (NAC) for $1 \mathrm{~h}$ and then exposed to $40 \mu \mathrm{M}$ cisplatin for $8 \mathrm{~h}$. The phosphorylation and expression levels of eIF $2 \alpha$ and p53 were examined by western blot analysis using anti-phospho-eIF2 $\alpha$ (Ser51), anti-eIF2 $\alpha$, anti-phospho-p53 (Ser15) and anti-p53 antibodies. The numbers below the bands indicate the relative density ratio of the respective protein normalized to the internal control ( $\beta$-actin). (C) The cells were pretreated with or without $5 \mu \mathrm{M} \mathrm{Sal003} \mathrm{for} 1 \mathrm{~h}$ and then exposed to $40 \mu \mathrm{M}$ cisplatin for $4 \mathrm{~h}$. (D) Cells transfected with $200 \mathrm{nM}$ control-siRNA or PKR-like endoplasmic reticulum kinase (PERK)-siRNA were incubated with or without $40 \mu \mathrm{M}$ cisplatin for $4 \mathrm{~h}$. ROS production was measured with the DCFH-DA fluorescence assay. Values are presented as means \pm SD, $n=3$. $P<0.05$ vs. cells treated with cisplatin alone. 
A
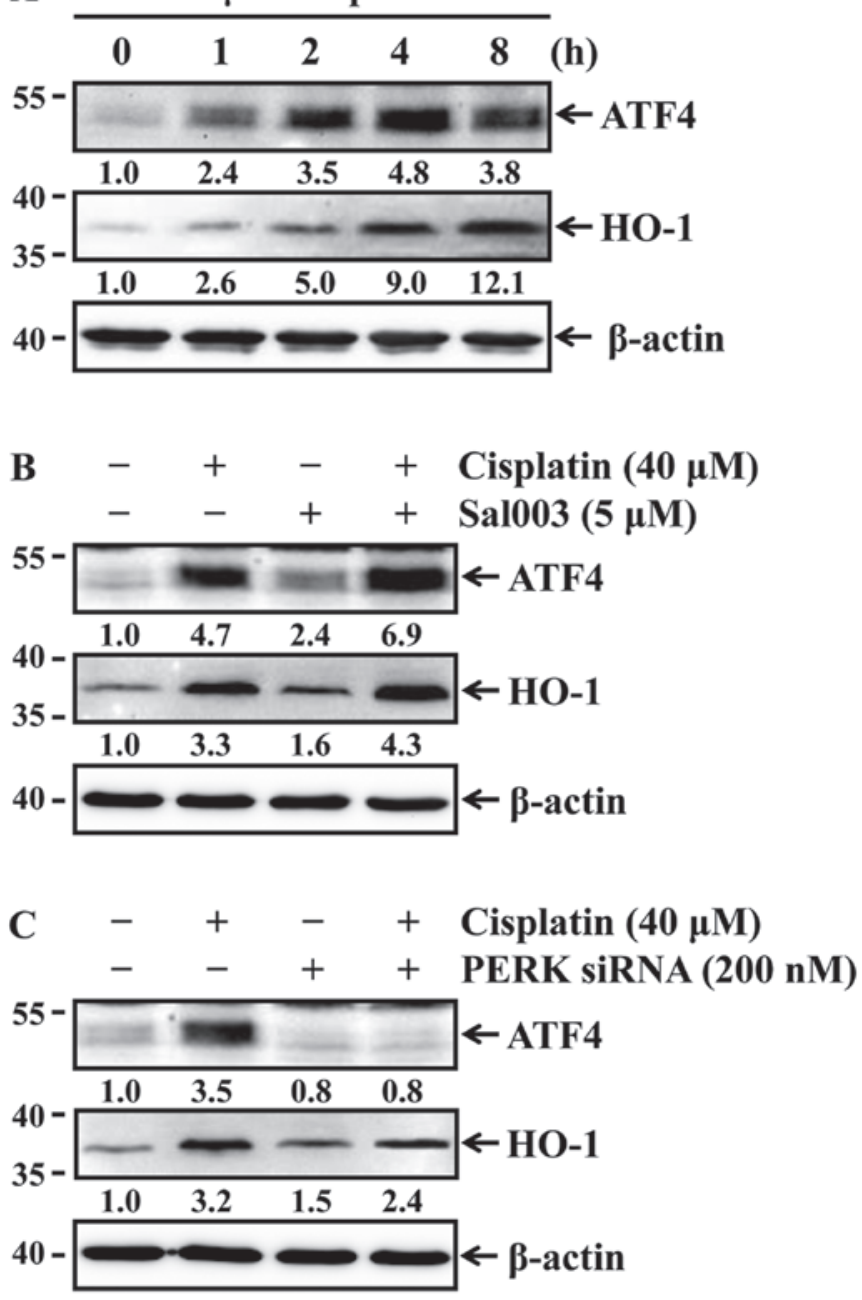

Figure 6. Effects of eukaryotic translation initiation factor $2 \alpha$ (eIF2 $\alpha$ ) phosphorylation on cisplatin-induced activating transcription factor 4 (ATF4) and heme oxygenase-1 (HO-1) expression in HK-2 cells. (A) The cells were incubated with $40 \mu \mathrm{M}$ cisplatin for the indicated times. (B) The cells were pretreated with or without $5 \mu \mathrm{M}$ Sal003 for $1 \mathrm{~h}$ and then exposed to $40 \mu \mathrm{M}$ cisplatin for $4 \mathrm{~h}$. (C) Cells transfected with $200 \mathrm{nM}$ control-siRNA or PKR-like endoplasmic reticulum kinase (PERK)-siRNA were incubated with or without $40 \mu \mathrm{M}$ cisplatin for $4 \mathrm{~h}$. The expression levels of ATF and HO-1 were examined by western blot analysis using anti-ATF4 and anti-HO-1 antibodies. The numbers below the bands indicate the relative density ratio of the respective protein normalized to the internal control ( $\beta$-actin).

\section{Discussion}

Nephrotoxicity is one of the main side effects that limit the therapeutic efficacy of the antineoplastic drug cisplatin (1-6). ROS and p53 have been found to be leading causes of cisplatin nephrotoxicity (8-15). Previous reported studies have demonstrated that cisplatin induces apoptotic cell death through ROS-mediated p53 activation in renal cells (13-15). In the present study, the roles of ROS and p53 in cisplatin-induced apoptosis of human renal proximal epithelial cells were investigated and the results demonstrated that cisplatin induced oxidative stress by increasing the production of intracellular ROS, which contributed to p53-mediated apoptosis of HK-2 cells. Furthermore, cisplatin-induced ROS production was involved in ER stress-mediated eIF2 $\alpha$ phosphorylation, which in turn suppressed p53 activation in HK-2 cells.
The phosphorylation of eIF $2 \alpha$ primarily plays a cytoprotective role against stress by attenuating global translation (20). Previous studies have reported that phosphorylation of eIF2 $\alpha$ protected cells against glucose deprivation stress and ER stress (26-28). Our results demonstrated that phosphorylation of eIF $2 \alpha$ protected HK-2 cells against cisplatin-induced apoptosis through reduction of p53 activation. By contrast, dephosphorylation of eIF2 $\alpha$ aggravated cisplatin-induced apoptosis in HK-2 cells by enhancing p53 activation. Similar to our results, Lee and Kim reported that salubrinal, an inhibitor of eIF2 $\alpha$ dephosphorylation, attenuated statin-induced apoptosis by inhibiting the stabilization of p53 (21). Thus, it is most likely that phosphorylation of eIF $2 \alpha$ contributes to the protection of HK-2 cells against cisplatin cytotoxicity. However, excessive phosphorylation of eIF $2 \alpha$ may negatively affect cytoprotection and cell survival. It was demonstrated that salubrinal enhances cisplatin-induced nephrotoxicity in mouse kidneys, indicating that excessive eIF $2 \alpha$ phosphorylation may be poorly tolerated by renal cells and exacerbate cisplatin-induced apoptosis (29).

Oxidative stress refers to elevated intracellular levels of ROS that may activate signaling pathways involving p53 phosphorylation and activation (30). Similar to previous studies (13-15), our results demonstrated that cisplatin induced apoptotic cell death in HK-2 cells through ROS-mediated p53 activation. Oxidative stress may also lead to phosphorylation of eIF2 $\alpha$ via PERK activation, which enhances the translation of ATF4 (31). The phosphorylation of eIF2 $\alpha$ has been shown to be crucial for the selective translational induction of ATF4 during ER stress (32). In accordance with those findings, our results demonstrated that cisplatin-induced oxidative stress was involved in eIF $2 \alpha$ phosphorylation, thus leading to increased ATF4 expression in HK-2 cells. It is noteworthy that ATF4 regulates the expression of several antioxidant genes in response to oxidative stress, which plays a central role in antioxidant responses (24). In particular, ATF4 may induce the expression of the antioxidant gene HO-1 in response to oxidative stress $(24,25)$. Dey et al reported that ATF4 induces expression of $\mathrm{HO}-1$ in response to matrix detachment-activated oxidative stress in human fibrosarcoma cells (24). He et al also reported that ATF4 regulates basal and $\mathrm{CdCl}_{2}$-induced expression of the HO-1 gene in a cell-specific manner (25). In the present study, cisplatin induced HO-1 expression, which was partially regulated by the eIF $2 \alpha$-ATF4 pathway in HK-2 cells. HO-1 has been shown to exert renoprotective effects through a potent antioxidant pathway in cisplatin-induced nephrotoxicity (8). Agarwal et al reported that the early induction of HO-1 plays an important role in cytoprotection against cisplatin-induced acute kidney injury (33). Thus, it is most likely that the phosphorylation of eIF $2 \alpha$ suppresses cisplatin-induced $\mathrm{p} 53$ activation by attenuating oxidative stress via the ATF4-mediated HO-1 expression in HK-2 cells, thereby resulting in protection against apoptosis.

In conclusion, cisplatin-induced oxidative stress leads to accumulation and activation of p53, leading to induction of apoptosis in HK-2 cells, while interfering with p53 activation through induction of eIF $2 \alpha$ phosphorylation. Interference in p53 activation by eIF $2 \alpha$ phosphorylation may be associated with expression of ATF4 and HO-1 in HK-2 cells exposed to cisplatin. In other words, the phosphorylation of eIF $2 \alpha$ may inhibit cisplatin-induced p53 activation and apoptosis 
by attenuating oxidative stress via the ATF4-mediated HO-1 expression in HK-2 cells. Therefore, the phosphorylation of eIF $2 \alpha$ may play an important role in protective strategies to alleviate cisplatin nephrotoxicity.

\section{Acknowledgements}

The present study was supported by the Basic Science Research Program through the National Research Foundation of Korea (NRF) funded by the Ministry of Education (grant nos. 2017R1A5A2015805 and 2013R1A1A2064013).

\section{References}

1. Kelland L: The resurgence of platinum-based cancer chemotherapy. Nat Rev Cancer 7: 573-584, 2007.

2. Barabas K, Milner R, Lurie D and Adin C: Cisplatin: A review of toxicities and therapeutic applications. Vet Comp Oncol 6: $1-18,2008$.

3. Hanigan $\mathrm{MH}$ and Devarajan P: Cisplatin nephrotoxicity: Molecular mechanisms. Cancer Ther 1: 47-61, 2003.

4. McWhinney SR, Goldberg RM and McLeod HL: Platinum neurotoxicity pharmacogenetics. Mol Cancer Ther 8: 10-16, 2009.

5. Rybak LP: Mechanisms of cisplatin ototoxicity and progress in otoprotection. Curr Opin Otolaryngol Head Neck Surg 15: 364-369, 2007.

6. Cubeddu LX: Mechanisms by which cancer chemotherapeutic drugs induce emesis. Semin Oncol 19 (Suppl 15): 2-13, 1992.

7. Yao X, Panichpisal K, Kurtzman N and Nugent K: Cisplatin nephrotoxicity: A review. Am J Med Sci 334: 115-124, 2007.

8. Pabla N and Dong Z: Cisplatin nephrotoxicity: Mechanisms and renoprotective strategies. Kidney Int 73: 994-1007, 2008.

9. Casares C, Ramírez-Camacho R, Trinidad A, Roldán A, Jorge E and García-Berrocal JR: Reactive oxygen species in apoptosis induced by cisplatin: Review of physiopathological mechanisms in animal models. Eur Arch Otorhinolaryngol 269: 2455-2459, 2012.

10. Conklin KA: Dietary antioxidants during cancer chemotherapy: Impact on chemotherapeutic effectiveness and development of side effects. Nutr Cancer 37: 1-18, 2000.

11. Sahin K, Sahin N and Kucuk O: Lycopene and chemotherapy toxicity. Nutr Cancer 62: 988-995, 2010.

12. Bhatt K, Zhou L, Mi QS, Huang S, She JX and Dong Z: MicroRNA-34a is induced via p53 during cisplatin nephrotoxicity and contributes to cell survival. Mol Med 16: 409-416, 2010.

13. Jiang $M$, Wei Q, Pabla N, Dong G, Wang CY, Yang T, Smith SB and Dong Z: Effects of hydroxyl radical scavenging on cisplatin-induced p53 activation, tubular cell apoptosis and nephrotoxicity. Biochem Pharmacol 73: 1499-1510, 2007.

14. Sánchez-Pérez Y, Morales-Bárcenas R, García-Cuellar CM, López-Marure R, Calderon-Oliver M, Pedraza-Chaverri J and Chirino YI: The alpha-mangostin prevention on cisplatin-induced apoptotic death in LLC-PK1 cells is associated to an inhibition of ROS production and p53 induction. Chem Biol Interact 188: 144-150, 2010.

15. Ju SM, Pae HO, Kim WS, Kang DG, Lee HS and Jeon BH: Role of reactive oxygen species in p53 activation during cisplatin-induced apoptosis of rat mesangial cells. Eur Rev Med Pharmacol Sci 18: 1135-1141, 2014.

16. $\mathrm{Xu} \mathrm{Y,} \mathrm{Wang} \mathrm{C} \mathrm{and} \mathrm{Li} \mathrm{Z:} \mathrm{A} \mathrm{new} \mathrm{strategy} \mathrm{of} \mathrm{promoting} \mathrm{cisplatin}$ chemotherapeutic efficiency by targeting endoplasmic reticulum stress. Mol Clin Oncol 2: 3-7, 2014.
17. Peyrou M and Cribb AE: Effect of endoplasmic reticulum stress preconditioning on cytotoxicity of clinically relevant nephrotoxins in renal cell lines. Toxicol In Vitro 21: 878-886, 2007.

18. Cybulsky AV: Endoplasmic reticulum stress in proteinuric kidney disease. Kidney Int 77: 187-193, 2010.

19. Back SH, Scheuner D, Han J, Song B, Ribick M, Wang J, Gildersleeve RD, Pennathur S and Kaufman RJ: Translation attenuation through eIF2alpha phosphorylation prevents oxidative stress and maintains the differentiated state in beta cells. Cell Metab 10: 13-26, 2009.

20. Qu L, Huang S, Baltzis D, Rivas-Estilla AM, Pluquet O, Hatzoglou M, Koumenis C, Taya Y, Yoshimura A and Koromilas AE: Endoplasmic reticulum stress induces p53 cytoplasmic localization and prevents p53-dependent apoptosis by a pathway involving glycogen synthase kinase-3beta. Genes Dev 18: 261-277, 2004.

21. Lee SK and Kim YS: Phosphorylation of eIF2 $\alpha$ attenuates statin-induced apoptosis by inhibiting the stabilization and translocation of p53 to the mitochondria. Int J Oncol 42: 810-816, 2013.

22. She QB, Chen N and Dong Z: ERKs and p38 kinase phosphorylate $\mathrm{p} 53$ protein at serine 15 in response to $\mathrm{UV}$ radiation. J Biol Chem 275: 20444-20449, 2000.

23. Hetz C, Chevet E and Harding HP: Targeting the unfolded protein response in disease. Nat Rev Drug Discov 12: 703-719, 2013.

24. Dey S, Sayers CM, Verginadis II, Lehman SL, Cheng Y, Cerniglia GJ, Tuttle SW, Feldman MD, Zhang PJ, Fuchs SY, et al: ATF4-dependent induction of heme oxygenase 1 prevents anoikis and promotes metastasis. J Clin Invest 125: 2592-2608, 2015.

25. He CH, Gong P, Hu B, Stewart D, Choi ME, Choi AM and Alam J: Identification of activating transcription factor 4 (ATF4) as an Nrf2-interacting protein. Implication for heme oxygenase-1 gene regulation. J Biol Chem 276: 20858-20865, 2001.

26. Scheuner D, Song B, McEwen E, Liu C, Laybutt R, Gillespie P, Saunders T, Bonner-Weir S and Kaufman RJ: Translational control is required for the unfolded protein response and in vivo glucose homeostasis. Mol Cell 7: 1165-1176, 2001

27. Muaddi H, Majumder M, Peidis P, Papadakis AI, Holcik M, Scheuner D, Kaufman RJ, Hatzoglou M and Koromilas AE: Phosphorylation of eIF2 $\alpha$ at serine 51 is an important determinant of cell survival and adaptation to glucose deficiency. Mol Biol Cell 21: 3220-3231, 2010.

28. Boyce M, Bryant KF, Jousse C, Long K, Harding HP, Scheuner D, Kaufman RJ, Ma D, Coen DM, Ron D, et al: A selective inhibitor of eIF2alpha dephosphorylation protects cells from ER stress. Science 307: 935-939, 2005.

29. Wu CT, Sheu ML, Tsai KS, Chiang CK and Liu SH: Salubrinal, an eIF2 $\alpha$ dephosphorylation inhibitor, enhances cisplatin-induced oxidative stress and nephrotoxicity in a mouse model. Free Radic Biol Med 51: 671-680, 2011

30. Martindale JL and Holbrook NJ: Cellular response to oxidative stress: signaling for suicide and survival. J Cell Physiol 192: $1-15,2002$.

31. Velasco G: Endoplasmic reticulum stressed by pollution. Focus on 'Airborne particulate matter selectively activates endoplasmic reticulum stress response in the lung and liver tissues'. Am J Physiol Cell Physiol 299: C727-C728, 2010.

32. Blais JD, Filipenko V, Bi M, Harding HP, Ron D, Koumenis C, Wouters BG and Bell JC: Activating transcription factor 4 is translationally regulated by hypoxic stress. Mol Cell Biol 24: 7469-7482, 2004.

33. Agarwal A, Balla J, Alam J, Croatt AJ and Nath KA: Induction of heme oxygenase in toxic renal injury: a protective role in cisplatin nephrotoxicity in the rat. Kidney Int 48: 1298-1307, 1995. 